\title{
PERCEPCIÓN VISUAL Y TRADUCCIÓN AUDIOVISUAL: LA MIRADA DIRIGIDA
}

\author{
Christina Lachat Leal \\ Universidad de Granada (España) \\ clachat@ugr.es
}

\section{Resumen}

En este trabajo, partimos de la premisa de que las destrezas perceptuales innatas necesarias para entender una obra audiovisual son idénticas a las de la percepción visual natural (Grodal 1999: 76). La percepción es una forma inconsciente y natural de interpretar nuestro entorno gracias a la experiencia previa y al aprendizaje. Sostenemos, en contra de la creencia profundamente arraigada en Occidente de que la imagen es universal y verdadera, que la percepción visual es un proceso cognitivo determinado por la experiencia previa, el ambiente, el contexto, los valores culturales y la motivación. En este trabajo vamos a estudiar la aplicación de las investigaciones cognitivas sobre percepción visual en las estrategias narrativas audiovisuales, así como sus implicaciones en el estudio del proceso de traducción audiovisual y en el de su recepción.

\begin{abstract}
"Visual perception and audiovisual translation: directed vision"

This paper is based on the premise that "some of the basic skills needed to understand film and television are identical to those necessary for natural visual perception" (Grodal 1999: 76). Perception is an unconscious and natural way of interpreting our environment based on prior experience and learning. In contrast to the deeply rooted Western belief that image is universal and true, our argument is that visual perception is a cognitive process determined by prior experience, environment, context, cultural values and motivation. This paper analyzes the application of cognitive research on visual perception in audiovisual narrative strategies and its implications for the study of the audiovisual translation process and of its reception.
\end{abstract}


Palabras clave: Traducción audiovisual. Narración visual. Análisis fílmico. Cógnito. Esquema perceptual.

Keywords: Audiovisual translation. Visual narration. Film analysis. Cognit. Perceptual scheme.

Manuscript received on March 29, 2011; Definitely accepted on November 15, 2011. 


\section{Introducción}

Tema de muchos tratados filosóficos desde Aristóteles, y objeto de un gran volumen de experimentación en psicología, la percepción visual sigue siendo una gran desconocida fuera de los ámbitos especializados. Por ello, y a pesar de las numerosas evidencias contrarias, algunas, como las ilusiones ópticas, muy conocidas por el gran público (recordemos la famosa copa de Rubin utilizada por la Gestalt), perduran dos creencias sobre la percepción visual: todos vemos lo mismo; la imagen es, pues, universal. Lo que vemos es la realidad, por lo tanto la imagen no miente. Estas creencias están tan profundamente arraigadas en nuestra manera de pensar que creemos más lo que vemos que lo que oímos. En nuestra opinión, también ha incidido en los enfoques analíticos de la traducción audiovisual al considerarla una traducción subordinada.

La percepción es un proceso cognitivo básico y complejo que permite interpretar y comprender la información recibida a través de los sentidos. Es una forma innata y natural de interpretar el entorno, esencial para nuestra supervivencia. Para seguir y entender una obra audiovisual utilizamos destrezas perceptuales innatas idénticas a las de la percepción visual natural (Grodal 1999: 76); pero, a diferencia de la natural, la percepción de la obra audiovisual la conduce un narrador que se apoya en los mecanismos de la percepción natural con la intención de dirigir la atención del espectador mediante estrategias narrativas perceptuales, que son el resultado de una simbiosis entre los distintos elementos narrativos, visuales y auditivos (imagen, música, sonido ambiente, voz).

Tal como señalaba Bravo (2003), las investigaciones sobre traducción audiovisual no han abordado en profundidad ni el estudio del lenguaje fílmico y sus estrategias narrativas, ni la subordinación de la traducción a la imagen y los problemas que esta plantea. Incluso podríamos añadir que resulta llamativa la cantidad de trabajos de investigación que analizan diálogos doblados o subtítulos sin ofrecer un análisis de los elementos narrativos de la imagen o, ni siquiera, una simple descripción de la imagen. Es muy posible que una de las razones sea la falta de un marco teórico consistente para el análisis de la imagen. 
El cine solamente tiene un siglo de antigüedad, y otros medios audiovisuales, menos de 50 años, lo que es poco tiempo en términos de investigación. Sin embargo, en los últimos años las aportaciones en este campo han evolucionado rápidamente gracias a los grandes avances técnicos que han propiciado, por una parte, el desarrollo vertiginoso de los soportes audiovisuales $\mathrm{y}$, por otra, los grandes avances en neurociencia gracias a la imagen por resonancia magnética funcional.

En este trabajo, en primer lugar repasaremos los principios de la psicología cognitiva sobre la percepción. En segundo lugar, ofreceremos una propuesta para analizar las estrategias narrativas fílmicas mediante la aplicación de los principios de la percepción y sus estrategias perceptivas. Por último, como creemos que las investigaciones en traducción audiovisual deberían dejar de considerar la imagen como una secundaria de lujo y abordar la creación de una metodología de análisis específica de la traducción audiovisual que incluya la percepción visual, señalaremos algunas posibles aplicaciones de nuestra propuesta a la traducción audiovisual.

\section{Percepción}

La percepción es un proceso cognitivo primario anterior al lenguaje y que ha formado parte de nuestra evolución. Los avances en neurociencia en los últimos tiempos facilitan la comprensión de este proceso cognitivo, a la vez extremadamente complejo y primario.

Según Fuster (2010), las memorias y objetos mentales de conocimiento están constituidos por amplias redes de neuronas, llamadas cógnitos, que se van asociando entre sí con la experiencia ambiental y educativa del individuo para, de este modo, formar redes más amplias. Es un proceso acumulativo constante en el que cógnitos nuevos modifican o sustituyen a los viejos. Los estímulos externos coincidentes no solo se asocian entre sí, sino que también lo hacen con redes preexistentes que contienen elementos semejantes. Esta capacidad combinatoria es prácticamente infinita e idiosincrásica (Fuster 2007: 61).

Un cógnito es una unidad de conocimiento o de memoria en la corteza cerebral, que contiene asociados entre sí todos los elementos de la percepción o acción relacionados con un hecho, un objeto, un acontecimiento vivido o una experiencia (Fuster 2010: S4).

Las redes se estructuran en dos jerarquías con base sensorial y motora. La jerarquía perceptual representa cógnitos definidos por parámetros sensoriales primarios y cógnitos perceptivos individuales. Como base de partida de todas las memorias, tanto perceptuales como ejecutivas, está la memoria filética, 
que es parte de la memoria genética adquirida en el curso de la evolución como medio de adaptación al medioambiente. Esta memoria innata se reactiva con actos perceptivos o motores. Mucha de esta activación es inconsciente como la percepción de eventos ordinarios salvo que ocurra algo inesperado (Fuster 2010: S6-7).

\subsection{Acto de ver}

Dentro de los estudios de la psicología cognitiva dedicados a los procesos cognitivos de la percepción, encontramos dos teorías: la ecologista y la constructivista. Descartamos la primera por arbitraria y contraria a las evidencias de la neurociencia, ya que postula que la percepción es un proceso directo sin construcción y que almacenamos la información tal como la percibimos. Para la segunda el proceso de ver es activo, y nuestra visión del mundo se construye con información del entorno y con información almacenada; la percepción no es una copia de la realidad, sino una representación de la realidad que debe ser interpretada. Esta propuesta supuso un giro respecto al enfoque tradicional del estudio de la percepción visual, ya que hasta entonces el modelo predominante partía del supuesto de que los mecanismos cognitivos de la percepción son pasivos y que vemos lo que nuestros ojos ven.

Ilustramos este cambio de perspectiva con una representación didáctica del sistema visual muy difundida en los libros de texto de los años 70 . Se trataba de una imagen muy similar a la de la ilustración 1 . Según esta, el estímulo visual (A) se transforma en la imagen invertida de una silueta de mujer (B) en el propio ojo, y el cerebro se limita a invertirla.

Gracias a los grandes avances tecnológicos de las últimas décadas, las investigaciones en neurología y neurobiología han demostrado que no son los ojos los que ven, sino el cerebro: la corteza visual, para ser precisos. El

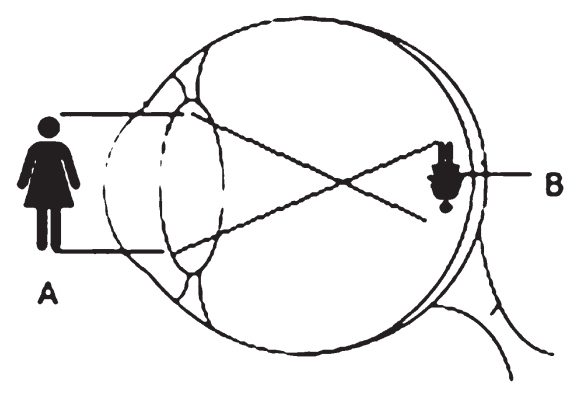

Ilustración 1 


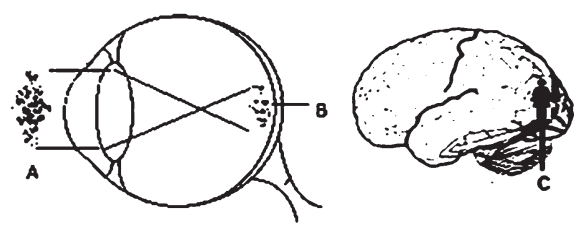

Ilustración 2

ojo recibe el brillo de la luz, sus células fotorreceptoras responden al estimulo luminoso mediante un impulso nervioso que, a su vez, sale del ojo por el nervio óptico y llega a la corteza visual, donde se interpretan estos impulsos y se produce la visión. En la ilustración 2 hemos esquematizado de forma rudimentaria ese proceso. A y B representan el brillo de la luz captada por el ojo, y $C$ es el resultado de la interpretación visual, la imagen de una silueta de mujer.

Como se puede apreciar, la percepción visual no es pasiva, sino que está motivada, tiene intención, es un acto, el acto de ver; dicho de otro modo, vemos lo que queremos ver. Pero no somos conscientes de este proceso, salvo que ocurra algo inesperado, ya que es un acto automático y reflejo (Fuster 2010: S7).

\subsection{Esquemas perceptuales}

La percepción es una actividad esencial para la adaptación del organismo a un entorno específico, y, dado que ese entorno es cambiante, la actividad perceptual debe adaptarse a esos cambios. Percibir es, pues, una construcción del sujeto que deriva de la relación establecida entre presente y pasado, y que depende de la habilidad y experiencia del perceptor (Neisser 1976). La percepción depende de estructuras preexistentes, denominadas esquemas, las cuales dirigen la actividad perceptual y se modifican en su transcurso. El esquema integra la información que llega a los sentidos y se transforma a causa de esa información; ese mismo esquema dirige los movimientos y las actividades exploratorias para tener acceso a una información posterior que acaba modificando el esquema (Neisser 1981: 67).

Al constituir un esquema anticipatorio, el perceptor se centra en un acto que compromete tanto a la información del ambiente como a sus propios mecanismos cognitivos. Es transformado por la información que adquiere. La transformación no es una cuestión de crear una réplica interna donde anteriormente no existía nada, sino más bien de alterar el esquema perceptivo de tal modo que el siguiente acto siga un curso distinto (Neisser 1981: 70). 
El esquema perceptual es una estructura activa de búsqueda de información mediante la detección y análisis de la información relevante de nuestro entorno para anticipar efectos, que, a su vez, modifican el esquema en un proceso circular, denominado ciclo percepción-acción (Neisser 1981), ciclo que no necesita de la consciencia (Fuster 2010: S7).

\subsection{Percepción del color}

Aunque aún estemos lejos de saber a ciencia cierta cómo funciona nuestro cerebro, la neurobiología nos ha aportado pruebas muy valiosas sobre la percepción del color, la cual nos sirve para ilustrar lo que acabamos de plantear.

Tal como apuntaba Goethe cuando dijo que "los colores son acciones y tormentos de la luz" (Aparici y García 2009: 82), sabemos que la luz es la fuente de los colores y que su reflexión en los objetos iluminados determina la percepción del color de una superficie. Pero también sabemos que la cantidad de luz reflejada en una superficie cambia continuamente, lo que plantea inquietantes interrogantes: ¿por qué no percibimos esos cambios en la coloración de una superficie?, ¿por qué nuestro jersey rojo favorito sigue siendo rojo bajo la luz del sol y bajo la luz de un fluorescente, y, en el mejor de los casos, solo percibimos un ligero cambio en la tonalidad? Cierto es que, como apunta sensatamente el neurobiólogo Zeki (2000: 4), "el mundo se volvería un lugar muy extraño si el color de una superficie se alterara con cada cambio en la composición de la luz".

Gracias a las técnicas de imágenes diagnósticas de los procesos cerebrales, se ha localizado el centro neurálgico donde se produce la operación que permite percibir el color o construirlo: el complejo V4. El hecho de que el complejo V4 resulta fundamental para la construcción del color se hace patente en los casos clínicos descritos sobre pacientes con lesiones en esa zona y con aparato visual de retina normal, pacientes que solo pueden percibir tonalidades de grises. El color no es en sí mismo una propiedad de los objetos, sino la interpretación que el cerebro hace de esa propiedad y un eficiente mecanismo de señalización biológica (Zeki 2000). Así, la percepción del color tiene una función, es un acto de ver motivado por la necesidad de conocer las propiedades de las cosas de manera instantánea y muy eficiente. Por ejemplo, existe la teoría de que la mayor facilidad de la que gozan las mujeres para percibir colores tiene su origen en la época neolítica, cuando una de las tareas femeninas principales era la recolección, por lo que necesitaban localizar rápidamente las frutas entre la vegetación y distinguir su punto de maduración (Gegenfurtner y Rieger 2000). 
Si el color no es una propiedad de los objetos sino una interpretación de nuestra mente, podemos deducir que nuestra percepción del color dependerá de factores evolutivos y ambientales, o, dicho de otra manera, de factores de origen genético, social o cultural.

Esto último no sorprenderá a los lingüistas, ya que la lingüística antropológica ha dedicado muchos estudios a las diferencias de categorización léxica del color entre distintas lenguas, hecho bien conocido por los traductores y que plantea que el lenguaje determina nuestra percepción del color. Aunque aceptamos que la lengua pueda determinar en alguna medida algunos de nuestros procesos cognitivos, no podemos suscribir esa teoría, entre otras razones porque sería tanto como decir que antes de la aparición del lenguaje no podíamos percibir los colores. Ello contradice el papel esencial que ha desempeñado la percepción en la supervivencia de la especie, y en particular el de la percepción visual del color en el éxito evolutivo de la especie humana.

Por todo ello, sostenemos que la percepción del color, y, por ende, de unos colores determinados y no otros, es intencionada y responde a su utilidad para desenvolvernos en nuestro entorno natural o en la sociedad. La percepción puede estar determinada genéticamente y puede aprenderse socialmente.

\section{Percepción y comunicación audiovisual}

Tal como dijimos en la introducción, consideramos que las destrezas perceptuales necesarias para entender una obra audiovisual son idénticas a las de la percepción natural, por lo que la comunicación audiovisual se rige por los mecanismos de la percepción natural. Al contrario del lenguaje, forma de comunicación consciente mediante una construcción arbitraria (la lengua), la comunicación audiovisual se basa en un proceso innato e inconsciente. Por ello, el esfuerzo cognitivo necesario para el aprendizaje de la lengua escrita es mayor que el de la oral, que aplica en mayor grado estrategias de percepción.

Si bien la comunicación audiovisual se basa en la percepción natural, a diferencia de la natural el espectador no selecciona la información más relevante ni busca la información. Uno de los logros de este tipo de comunicación es conseguir, mediante unas estrategias narrativas perceptivas visuales y sonoras, que el espectador tenga la ilusión de percibir de forma natural. A lo largo de los años, los directores han desarrollado un gran número de técnicas cinematográficas para dirigir la mente del espectador durante el visionado (Hasson et al. 2008: 1), arsenal que algunos de ellos aplican con gran maestría. Tanto es así, que grandes películas tienen grandes errores o fallos que pasan desapercibidos por completo para la inmensa mayoría de los espectadores, salvo que 
intencionadamente los busquen. Por ejemplo, la película Apocalypse Now, de Francis Ford Coppola, tiene un total de 391 errores.

Planteamos la hipótesis de que la comunicación audiovisual utiliza dos tipos de estrategias narrativas audiovisuales para dirigir la percepción del espectador, unas que simulan los procesos perceptivos naturales y se basan en esquemas preexistentes (cf. apartado 2.1) y otras propias que crean nuevos esquemas perceptuales (cf. apartado 2.2).

\subsection{Simulación de la percepción natural}

Ocurre cuando el narrador es más invisible, cuando la cámara se convierte en los ojos del espectador. Se trata de presentar una imagen icónica y dejar que el espectador extraiga información relevante sobre situación geográfica, temporalidad, personajes. Es muy efectiva en la narración fílmica porque, en unos segundos, se puede situar una acción y localizarla en el tiempo. Por ejemplo, tomemos la primera secuencia de la película Potiche, dirigida por François Ozon (2010):

Una mujer de unos sesenta años haciendo jogging pasa delante de una fábrica y entra en una mansión. Delante de la mansión al lado de unos setos muy bien recortados vemos dos coches, uno negro y otro con el techo blanco y rojo estilo años 70 .

En un solo plano hemos situado la época, los años 1970 y sabemos que la protagonista es una persona acomodada, seguramente de clase media alta. Asimismo, esta estrategia puede utilizarse con fines mucho más dramáticos en la narración fílmica. Cuando percibimos una imagen no pensamos que representa algo más, y, si el narrador cinematográfico nos presenta una imagen icónica, nos limitamos a aplicar esquemas perceptuales adecuados para analizar las señales ambientales que nos transmite la imagen sin doble intención. Si en la siguiente imagen o plano el narrador rompe esta representación, conseguirá sorprendernos y emocionarnos.

\subsubsection{Esquemas filéticos}

En este caso, esta estrategia recurre a nuestra memoria genética mediante la activación de un esquema filético. Por ejemplo, con el uso de la iluminación, en concreto de las sombras y los claroscuros, se activa un esquema filético de peligro, incertidumbre que incluso se ha reforzado en la actualidad por el hecho de que disfrutamos de un entorno muy iluminado. 


\subsubsection{Esquemas de percepción antropomórfica}

Otra estrategia consiste en utilizar nuestros esquemas de percepción antropomórfica (Grodal 1999: 90), esquemas que aplicamos inconscientemente al ver una película, por esa razón identificamos el campo de la imagen con nuestro campo visual, y "nos hace creer que este espacio no se detiene en los bordes del marco, sino que se prolonga indefinidamente" (Aumont 1992: 232). Una estrategia antropomórfica muy expresiva es la que sitúa un elemento fuera de campo, detrás de la cámara, es decir, a nuestras espaldas. Otros ejemplo son el ángulo en picado, que permite una visión desde lo alto, que minimiza un personaje o banaliza una situación, y, al contrario, el contrapicado, que engrandece el personaje o magnifica cualquier otro elemento.

\subsubsection{Esquemas culturales y sociales}

La imagen icónica que se menciona en el primer ejemplo de este apartado activa un esquema cultural, una estrategia muy frecuente no solo para situar geográficamente un suceso, sino también para situar socialmente a los personajes. Puede ser un recurso sutil, como la imagen de la metamorfosis del paisaje a causa del paso de las estaciones, la del cambio en el vestuario o los accesorios -normalmente coches - para mostrar el ascenso social, o evidente, como la imagen de un reloj para marcar el tiempo.

Otra estrategia narrativa muy expresiva que activa esquemas culturales es el primer plano, con el que el espectador percibe el estado emocional de los personajes y que resulta más efectiva aún cuando las expresiones o gestos contradicen las palabras. Porque tanto los cineastas como los guionistas conocen y aplican el sentido de primacía de la percepción visual del espectador, es decir que este cree más lo que ve que lo que oye (Rodríguez 2009: 68).

Otra de las estrategias narrativas que se basan en esquemas culturales es el uso del color que transmite estados emocionales según su situación en la escala tonal superior o inferior.

\subsubsection{Esquemas anticipatorios}

Tal como vimos en el apartado dedicado a la percepción, la búsqueda de información para anticipar sucesos es el motivo principal del acto de ver. Por ello, es natural que muchas estrategias narrativas se fundamenten en esquemas anticipatorios, que, a su vez, pueden basarse en esquemas genéticos, culturales, sociales o, como veremos más adelante, específicamente audiovisuales. Aunque pueden valerse solo de una imagen, la mayoría de las estrategias anticipatorias combinan sonido e imagen. Es el caso de la música, que advierte 
al espectador de que algo malo va a ocurrir, o el sonido de una sirena, que anticipa la afluencia de personas. Otra estrategia aún más efectiva y dramática consiste en romper ese esquema anticipatorio: no hay nada más aterrador que el sonido de esa sirena acompañado de la imagen de unas calles desiertas.

\subsection{Percepción audiovisual adquirida}

"El cine reconstruye sistemas visuales que se corresponden con las reglas de la percepción, pero también a la inversa elabora una serie de convenciones a las que nos vamos adaptando hasta naturalizarlas" (Benet 2004: 201). Dentro de ese proceso circular que es el ciclo perceptivo, los esquemas, al no ser una representación estática de la realidad, poseen una alta capacidad de adaptación. No hacemos comparaciones, sino que somos capaces de reconocer nuevos estímulos e integrarlos en esquemas modificados que en el ámbito de la percepción audiovisual podríamos denominar esquemas fílmicos, esquemas televisivos, esquemas interactivos, etc.

Dicho de otra manera, hemos aprendido a ver películas, anuncios, documentales y videojuegos. Nuestra percepción audiovisual está en constante evolución, y algunos esquemas fílmicos y videográficos se transformarán en procesos perceptivos inconscientes. El primer plano, el gran primer plano y el plano detalle son ejemplos muy claros de estrategias narrativas visuales propias. A principios del siglo pasado "los primeros planos que encuadraban el busto, o incluso la cabeza, produjeron durante bastante tiempo una reacción de rechazo" (Aumont 1992: 149). Cine de ficción, documentales, series, programas televisivos y videojuegos comparten convenciones, pero también han creado sus propias convenciones, incluso cada género cinematográfico ha creado las suyas, por lo que se puede considerar la existencia de esquemas perceptivos fílmicos de terror, musicales, de animación, etc.

\section{Mirada dirigida y traducción}

Tal como planteamos en el apartado 2, las estrategias narrativas visuales se fundamentan en los esquemas perceptuales de los receptores de la obra audiovisual. Estos esquemas no son universales, sino que dependen de factores genéticos, culturales e individuales, entre ellos la propia experiencia audiovisual del espectador. Pero, aunque la percepción sea individual, genéticamente y físicamente nuestras diferencias son mínimas, casi irrelevantes. Esta similitud de los procesos perceptivos y su plasticidad producen una falsa sensación de simplicidad de estos procesos, lo que redunda en la sensación de que cualquiera es capaz de comprender una obra audiovisual sin conocer los 
mecanismos de la comunicación audiovisual. En esta falacia caen tanto los traductores y adaptadores como los espectadores de una obra doblada o subtitulada. Estos últimos siempre atribuirán una mala comprensión de la obra a una mala traducción y nunca se plantearán si se debe a una falta de destrezas perceptivas.

Por su parte, el traductor, al desconocer o ignorar las estrategias narrativas visuales debido a ese concepto de traducción audiovisual centrado en los elementos paraverbales - concepto que implícitamente conlleva la idea de que la traducción se limita a las palabras, que las imágenes simplemente complican más la tarea o incluso la hacen imposible y que, en última instancia, el traductor se debe al guión (Zabalbeascoa 2008: 33)—, no podrá considerar en qué medida estas estrategias afectarán a la recepción de su traducción, ni de qué modo influyen en su proceso de traducción, ya que él también es un espectador de la obra audiovisual.

Ahora bien, somos conscientes de que la sensación de que la imagen encorseta o complica la traducción procede del hecho de que nos faltan herramientas que nos permitan analizar las imágenes y detectar las diferencias perceptivas del espectador original y el de la traducción.

\subsection{Proceso de traducción audiovisual}

El traductor, como espectador de la obra audiovisual, verá su mirada dirigida mediante estrategias narrativas visuales salvo que sea capaz de detectarlas y analizarlas. Al ser la percepción visual un proceso inconsciente, si no localiza estas estrategias narrativas visuales se convierte en un receptor pasivo de la obra, con una visión parcial de la misma. En este caso, esa percepción inconsciente puede afectar a su toma de decisiones. Sokoli (2005) compara los subtítulos de la versión española y griega de cuatro fragmentos de la película El paciente inglés, comparación en la que encontramos un ejemplo interesante de connotación reproducida por la imagen que ha afectado al subtitulado.

En el primer ejemplo, el protagonista dice "I've got this much lung", haciendo un gesto con la mano que significa poco y esto se traduce por [...] (medio pulmón). Es decir, el traductor griego opta por explicar la información visual, aunque dicha información no se encuentra en el elemento acústicoverbal. (Sokoli 2005: 18)

Partimos de la premisa de que ese gesto forma parte de los esquemas perceptuales griegos, porque, en caso contrario, la autora lo hubiera señalado, por lo que planteamos la posibilidad de que el traductor no haya optado conscientemente por la explicitación de la imagen, sino que ha traducido directamente el mensaje que ha percibido, sin distinguir la fuente, visual o acústica. 
Por lo tanto, es importante que el traductor se convierta en receptor experto activo y que sea capaz de analizar la percepción de la obra audiovisual del mismo modo que el traductor de un texto escrito realiza un análisis textual del texto original. Al mismo tiempo que visiona la obra para comprobar si su copia del guión concuerda con la producción final de la obra, puede identificar los elementos constitutivos de la imagen que la dotan de sentido. Más adelante, podrá tener en cuenta estos elementos para tomar decisiones y solucionar problemas de traducción. La identificación de los esquemas culturales perceptivos que se activen al visionar la secuencia permitirá al traductor comparar los esquemas del espectador original con los del espectador de la traducción, con lo que podrá optar, en el mejor de los casos, por una solución que no desvíe la mirada del espectador y, cuando la desviación sea inevitable, reducirla al máximo.

Por ejemplo, en una serie rodada en un país nórdico, como Varg Veum, serie de televisión dirigida por Morten Tyldum (2008), la luz solar o su ausencia, que nos sitúan visualmente en un momento determinado del día o de la noche, activan esquemas filéticos que en un principio consideramos universales; sin embargo, puede producir un efecto perturbador para un espectador español por la presencia de elementos verbales y visuales incongruentes. Este efecto es inevitable, pero el traductor, al detectarlo, puede valorar su impacto en la narración y, en función del género — de ficción o documental—, de la escena y del valor narrativo de la imagen en relación con el guión, optar por la solución más apropiada y menos perturbadora.

Quisiéramos recordar que, por desgracia, en el proceso de traducción audiovisual el traductor no suele ser el responsable del producto final, salvo quizá en el caso del subtitulado, donde el ajustador suele limitarse a arreglos técnicos. En el proceso de traducción para doblaje, en el que los estudios encargan una traducción literal al traductor, es el adaptador el que toma las decisiones últimas de traducción. Aun en el supuesto en que el adaptador sea un receptor experto en lenguaje fílmico, es complejo llegar a adquirir las competencias suficientes en la cultura original para reconocer los esquemas perceptivos culturales y sociales de los receptores originales, y tampoco creemos que sea necesario que las tenga: sería suficiente poder contar con traductores audiovisuales competentes y trabajar en un entorno cooperativo.

\subsection{Recepción de la traducción audiovisual}

Pensamos que el análisis de los mecanismos de la percepción visual mediante los esquemas perceptuales podría ser de mucha utilidad en los estudios sobre la recepción de la traducción audiovisual, ya que puede evitar que el peso del análisis recaiga en la traducción del guión y que se pueda contemplar la 
relación entre la recepción del mensaje visual y auditivo. Un análisis sistemático de un corpus de obras originales y sus respectivas traducciones podría llegar a determinar, entre otros aspectos, si los posibles fallos en la recepción se deben a que la traducción haya desviado la atención del espectador de la dirección original, o bien si se deben a discrepancias insalvables entre los esquemas perceptivos de los receptores originales y los de los receptores de la traducción.

\subsection{Competencias audiovisuales del traductor}

Hemos puesto de manifiesto a lo largo de este trabajo que, en la percepción de la imagen intervienen factores genéticos, ambientales, culturales, sociales e individuales, y por ello la percepción de una misma imagen puede diferir de un espectador a otro. Por otro lado, hemos señalado que la percepción de una obra audiovisual está dirigida por un autor, que como cualquier otro autor piensa en un tipo de espectador concreto. Por lo tanto, nos parece fundamental integrar los elementos visuales en el proceso de traducción audiovisual. $\mathrm{Al}$ igual que al traductor de obras escritas se le exige un alto nivel de competencias lingüísticas en ambas lenguas, al traductor audiovisual se le deben exigir amplios conocimientos en lenguaje y análisis fílmico, lo que además redundaría en un mayor reconocimiento de la labor del traductor audiovisual.

Al hilo de esta cuestión, nos parece revelador el hecho de que, al contrario de lo que ocurre en la traducción literaria, donde es habitual que un traductor se especialice en un autor, en el caso de la traducción cinematográfica esa especialización es una excepción. Podemos mencionar el caso particular de Vicente Molina Foix, elegido por el cineasta Stanley Kubrick, muy conocido por su perfeccionismo y que daba tal valor al doblaje de sus películas que intervenía personalmente en el proceso, seleccionando personalmente a los directores de doblaje, actores y traductores.

\section{Conclusiones}

En esta primera aproximación hemos demostrado que el estudio de los esquemas perceptivos audiovisuales y su aplicación a la traducción audiovisual puede abrir nuevas vías en la investigación de la traducción audiovisual. En primer lugar, nos permitirá desarrollar en el futuro nuevas herramientas de análisis de la percepción de una obra audiovisual mediante la identificación de las estrategias narrativas que activan unos determinados esquemas perceptivos. Estas herramientas, a su vez, facilitarán el proceso y el estudio de la traducción audiovisual y podremos cambiar el concepto de traducción subordinada por el de traducción simbiótica. En segundo lugar, podremos aplicar 
los resultados de esta investigación para crear una metodología de análisis específica de la traducción audiovisual.

Además, creemos que su utilidad no se limita a la traducción como producto final, sino que podrá aplicarse a los estudios sobre la recepción de la audiodescripción y de la subtitulación para sordos, ya que, cuantas más diferencias haya entre los esquemas perceptivos de los espectadores, mayor será la importancia de estas estrategias narrativas.

Para terminar, queremos señalar que las perspectivas futuras de esta línea investigación son muy alentadoras gracias al auge de los estudios sobre percepción en distintas disciplinas, como neurología, neurobiología, neuroestética, psicología cognitiva, mercadotecnia y publicidad.

\section{Bibliografía}

APARICI, Roberto \& Agustín García Matilla. (2009) La imagen: análisis y representación de la realidad. Barcelona: Gedisa.

Aumont, Jacques. (1990) L'image. Paris: Édition Nathan. [Citado por la traducción española de Antonio López Ruiz: La imagen. Barcelona: Paidós, 1992.]

BENET, Vicente J. (2004) La cultura del cine: introducción a la historia y la estética del cine. Barcelona: Paidós Ibérica Ediciones SA.

BRAVO, José María. (2003) "La investigación en traducción audiovisual en España: los textos cinematográficos". En: García Peinado, Miguel Ángel \& Emilio Ortega Arjonilla (eds.) 2003. Panorama actual de la investigación en traducción e interpretación. Granada: Atrio. pp. 235-252.

FUSTER, Joaquín. (2007) "Cajal y la neurociencia cognitiva cien años más tarde". Quark 39-40. pp. 59-65.

FUSTER, Joaquín. (2010) "El paradigma reticular de la memoria cortical". Neurol. 50:3. pp. S3-10.

GEGENFURTNER, Karl R. \& Jochem Rieger. (2000) "Sensory and cognitive contributions of color to the recognition of natural scenes". Current Biology 10:13. pp. 805-808. Versión electrónica: <http://citeseerx.ist.psu.edu/viewdoc/down load?doi=10.1.1.37.4788\&rep=repl\&type=pdf>

GRODAL, Torben. (1999) Moving pictures: A new theory of film genres, feelings, and cognition. Oxford: Oxford University Press.

HASSON, Uri; Ohad Landesman; Barbara Knappmeyer; Ignacio Vallines; Nava Rubi \& David J. Heeger. (2008) "Neurocinematics: The neuroscience of film". Projections 2:1. pp.1-26.

NEISSER, Ulric. (1976) Cognition and reality: principles and implications of cognitive psychology. San Francisco: W. H. Freeman \& Co. [Citado por la traducción española de Manuel Ato García: Procesos cognitivos y realidad: principios e implicaciones de la psicología cognitiva. Madrid: Marova, 1981.] 
RODRÍGUEZ DE FONSECA, Francisco Javier. (2009) Cómo escribir diálogos para cine y televisión. Madrid: T\&B.

SoKoli, Stavroula. (2005) "Temas de investigación en la traducción audiovisual: la definición del texto audiovisual”. En: Zabalbeascoa, Patrick; Laura Santamaria \& Frederic Chaume (eds.) 2005. La traducción audiovisual: investigación, enseñanza y profesión. Granada: Comares. pp. 177-185.

ZABAlBEASCOA, Patrick. (2008) "The nature of the audiovisual text and its parameters". En: Díaz-Cintas, Jorge (ed.) 2008. The didactics of audiovisual translation. Amsterdam: John Benjamins. pp. 21-37.

ZEKI, Semir. (2000) "Esplendores y miserias del cerebro". En: Mora, Francisco \& José María Segovia de Arana (eds.) 2000. Ciencia y sociedad: "nuevos enigmas científicos”. Madrid: Fundación Santander Central Hispano. Versión electrónica: <http://neuroesthetics.org/pdf/esplendores.pdf>

\section{BIONOTE / NOTA BIOGRÁFICA}

\section{Christina Lachat Leal}

Christina Lachat Leal, PhD, teaches translation at the University of Granada since 1999. She has published several works related to cognitive translatology, problem solving, learning and expert knowledge in the context of the research team Petra (Expertise and environment in translation) including the book Identificación, representación y resolución de problemas de traducción (Identifying, representing and solving translation problems: an empirical study of the behavior of experts and novices). After her involvement in the research project TRACCE (Evaluation and management of accessibility resources for sensory disabled people through audiovisual translation), her research has incorporated visual perception and audiovisual translation.

La doctora Christina Lachat Leal, profesora del Departamento de Traducción e Interpretación de la Universidad de Granada desde el año 1999, ha publicado varios trabajos relacionados con la traductología cognitiva, la resolución de problemas, el aprendizaje y el conocimiento experto, en el marco del grupo de investigación Petra: Pericia y entorno de traducción, entre los cuales cabe destacar el libro Identificación, representación y resolución de problemas de traducción: estudio empírico del comportamiento de expertos y principiantes. Tras su participación en el proyecto TRACCE (Evaluación y gestión de los recursos de accesibilidad para discapacitados a través de la traducción audiovisual), sus líneas de investigación incluyen percepción visual y traducción audiovisual. 